\title{
Highly selective toxic and proapoptotic effects of two dimeric ribonucleases on thyroid cancer cells compared to the effects of doxorubicin
}

\author{
D Spalletti-Cernia', R Sorrentino', S Di Gaetano ${ }^{2}$, R Piccoli $^{2}$, M Santoro', G D'Alessio², P Laccetti and \\ G Vecchio*,1
}

'Istituto di Endocrinologia ed Oncologia Sperimentale del CNR clo Dipartimento di Biologia e Patologia Cellulare e Molecolare, Università di Napoli Federico II, via S. Pansini 5, 80131 Naples, Italy; ${ }^{2}$ Dipartimento di Chimica Biologica, Università di Napoli Federico II, Naples, Italy

\begin{abstract}
The lack of selectivity of conventional antitumour drugs against cancer cells is responsible for their high toxicity. The development of new tumour-specific drugs is therefore highly needed. We tested the cytotoxic effects and the nature of cell death induced by a naturally dimeric bovine RNase and a newly engineered dimeric human RNase upon three genetically well-defined normal and malignant thyroid cell systems. RNases effects were compared with those of doxorubicin, a conventional antineoplastic drug. Our results show significant and selective proapoptotic effects exerted on tumour cells by both RNases, the strength of their cytotoxic and apoptotic activity being directly related to the degree of cell malignancy. No toxic effects were observed upon normal cells. Doxorubicin showed, instead, cytotoxic and apoptotic effects also against normal cells. The in vitro results were corroborated by the antitumour action of both dimeric RNases towards a malignant human thyroid tumour grown in nude mice. These results indicate a selective action of dimeric RNases against cancer cells and suggest the potential application of these molecules or their derivatives to the treatment of aggressive subtypes of thyroid cancer.

British Journal of Cancer (2004) 90, 270-277. doi:I0.1038/sj.bjc.660I49I www.bjcancer.com

(c) 2004 Cancer Research UK
\end{abstract}

Keywords: cytotoxic RNases; cell malignancy; apoptosis; thyroid cells and tumours

Most of the known conventional antineoplastic drugs lack specificity against cancer cells, exerting instead unfavourable reactions in cancer patients due to their toxic effects on normal tissues (Hurley, 2002). Recent advances in cancer molecular biology allowed the discovery of discrete molecular lesions in key proteins responsible for the development of a fully aggressive cancer phenotype (Chabner et al, 1998; Gibbs, 2000). These advances have in turn led to the development of new anticancer drugs possessing selective activity towards tumour cells bearing those specific genetic lesions (Gibbs, 2000; Bange et al, 2001). By this approach, a successful treatment can be achieved only in those types of tumours bearing the genetic lesion specifically targeted by the drug.

Some ribonucleases are endowed with a strong antineoplastic activity. The best known members of this family are onconase, a protein extracted from Rana pipiens and currently tested in phase II and III clinical trials (Wu et al, 1993; Juan et al, 1998; Halicka et al, 2000, 2002; Lee et al, 2000; Mikulski et al, 2002; Saxena et al, 2002), and seminal ribonuclease, extracted from bull semen (BSRNase) (Youle and D'Alessio, 1997). BS-RNase, the only dimeric member of the pancreatic-type RNase superfamily (Beintema et al, 1997), is endowed with a strong cytotoxic activity against tumour

*Correspondence: Dr G Vecchio; E-mail: vecchio@unina.it Received 25 July 2003; revised 15 October 2003; accepted I5 October 2003 cells in vitro (Laccetti et al, 1992) and is active against cancer cells in vivo, as well (Laccetti et al, 1994). Through protein engineering, a new dimeric RNase of human nature, HHP2-RNase, has been derived from human pancreatic RNase (HP-RNase). This was achieved by replacing five HP-RNase amino-acid residues (Q28, $\mathrm{K} 31, \mathrm{~K} 32, \mathrm{~N} 34, \mathrm{E} 111$ ) with the corresponding residues (L28, C31, C32, K34, G111) from BS-RNase. HHP2-RNase was even more powerful as a cytotoxic agent than BS-RNase, and as selective for malignant cells (Piccoli et al, 1999; Di Gaetano et al, 2001). This protein has the obvious advantage over BS-RNase of being little or not immunogenic at all for humans.

The exact mechanism of the antitumour action of RNases remains to be clarified. The binding of BS-RNase to a component of the extracellular matrix (Mastronicola et al, 1995) and of onconase to an unidentified cell surface receptor (Wu et al, 1993) is followed by endocytosis, translocation to the cytosol, degradation of RNA (rRNA or tRNA by BS-RNase and onconase, respectively) and suppression of protein synthesis leading to cell death. BS-RNase is internalised and enclosed in endosomes in both normal and malignant cells. Only in malignant cells, however, the RNase is transported into the trans Golgi network, whence it is released in the cytosol (Bracale et al, 2002). The dimeric structure of BS-RNase and HHP2-RNase is essential to enter the cytosol (Murthy et al, 1996; Antignani et al, 2001; Leland et al, 2001). The cytosolic ribonuclease inhibitor (cRI) tightly binds to internalised ribonucleases, thus blocking their cytotoxic activity; only ribonucleases that can evade cRI are capable of exerting a cytotoxic 
action. Also, the resistance of BS-RNase to cRI inhibition depends on the dimeric structure of the enzyme (Murthy et al, 1996; Antignani et al, 2001; Leland et al, 2001). On the other hand, onconase, the frog ribonuclease, is inhibited by frog but not mammalian cRI.

To verify whether the antineoplastic activity of ribonucleases was exerted on malignant cells independently from their specific genetic lesions, we performed a systematic study of the effects of BS-RNase and HHP2-RNase against genetically well-defined systems of thyroid tumour cells. Thyroid tumours are the most prevalent endocrine malignancy and some subtypes, anaplastic and poorly differentiated carcinomas, are associated with significant morbidity and mortality (Hedinger et al, 1989). Three different cell systems were used, derived from rat (AmbesiImpiombato et al, 1980; Fusco et al, 1987; Portella et al, 1989) or human thyroid follicular cells (Kantor et al, 1978; Pang et al, 1989; Ishizaka et al, 1990; Gioanni et al, 1991; Curcio et al, 1994 and carrying as diverse genetic alterations as a gain-of-function of Kiras, N-ras, src, ret/ptc1 or B-Raf oncogenes or loss-of-function of p53. These cells display a full spectrum of progressive malignancy from normal differentiated, to immortalised, to oncogene-transformed, and to tumour- and metastasis-derived cells.

We show that HHP2-RNase and BS-RNase are highly cytotoxic for all tested tumour cell lines regardless of the specific genetic lesion carried by the target cells. Their activity was directly related to the degree of cell malignancy with no effects on the growth of normal cells. In stark contrast, doxorubicin showed its maximal cytotoxic effects against normal cells. A strong inhibitory activity was exerted by both RNases on the growth of tumours induced in nude mice, following subcutaneous (s.c.) injection of human thyroid carcinoma cells. The dimeric nature of the RNases scored essential for the antineoplastic effects, as no cytotoxic activity was exerted by monomeric RNases. These results suggest the potential utilisation of dimeric RNases for the therapy of aggressive human thyroid tumours, known to respond poorly to conventional chemotherapeutics.

\section{MATERIALS AND METHODS}

\section{Cell lines}

FRTL-5 is a normal, differentiated rat thyroid epithelial cell line (Ambesi-Impiombato et al, 1980). FRTL-5- $v$-src and FRTL-5- $v$-Kiras are in vitro $v$-src- and $v$-Ki-ras-transformed FRTL-5 cells (Fusco et al, 1987). TK-6 and MPTK-6 were derived from primary thyroid carcinomas and lung metastasis, respectively, induced in rats by the intrathyroid injection of the Kirsten Murine Sarcoma Virus (Portella et al, 1989). P5 is a primary culture of normal human differentiated thyrocytes (Curcio et al, 1994). HDF cells are normal human diploid fibroblasts (Kantor et al, 1978). The four human thyroid carcinoma-derived cell lines were Cal62 and ARO cells from anaplastic carcinomas (Pang et al, 1989; Gioanni et al, 1991) and NPA and TPC1 cells from papillary carcinomas (Pang et al, 1989; Ishizaka et al, 1990). Rat and human cell lines were cultured as previously reported (Kantor et al, 1978; AmbesiImpiombato et al, 1980; Fusco et al, 1987; Pang et al, 1989; Portella et al, 1989; Ishizaka et al, 1990; Gioanni et al, 1991; Curcio et al, 1994).

\section{Cell survival}

At day 0,100-500 cells (depending on the cell line) were plated. After 1 day, cells were treated for $24 \mathrm{~h}$ with increasing amounts of either ribonuclease (from $1.37 \mathrm{ng} \mathrm{ml}^{-1}$ to $13.7 \mu \mathrm{g} \mathrm{ml}^{-1}$ ) or doxorubicin (from $29 \mathrm{pg} \mathrm{ml}^{-1}$ to $290 \mathrm{ng} \mathrm{ml}^{-1}$ ) corresponding to final concentrations for both drugs ranging from 0.05 to $500 \mathrm{nM}$. After
2-3 weeks, colonies were stained with crystal violet and counted, as previously described (Spalletti-Cernia et al, 1995).

\section{Gel electrophoresis of fragmented DNA}

Agarose gel electrophoresis was performed as described by Hockenbery et al (1990). Briefly, DNA from control and treated cells $\left(1 \times 10^{6}\right.$ cells $)$ was extracted with phenol-chloroform, precipitated and subjected to electrophoresis on a $1.2 \%$ agarose gel. The agarose gel was stained with ethidium bromide and the resulting DNA fragmentation pattern was visualised by UV illumination.

\section{Fluorescence analysis of apoptosis}

Cells were plated on coverglasses in 24 -well plates and $24 \mathrm{~h}$ later, the RNase under test was added to a final concentration of 1.8. $\mu \mathrm{M}$. Following $72 \mathrm{~h}$ of treatment, cells were fixed in $3.7 \%$ formaldehyde in PBS for $15 \mathrm{~min}$ at room temperature. Cells were then permeabilised with $0.1 \%$ Triton $\mathrm{X}-100$ for $5 \mathrm{~min}$ at room temperature and stained for $30 \mathrm{~min}$ with Hoechst 33258 (Sigma Chemical Co.) at a concentration of $0.5 \mu \mathrm{g} \mathrm{ml}^{-1}$ in PBS. The stained cells were observed under an epifluorescent microscope (Axiovert 2, Zeiss) as previously reported (Piccoli et al, 1999).

\section{In vivo experiments}

Nude mice (5 weeks old) were injected s.c. at day 0 with $1 \times 10^{6}$ ARO cells (Pang et al, 1989). Mice were then treated with six injections in the peritumoral areas of $20 \mu \mathrm{g} \mathrm{g}^{-1}$ of body weight of RNases. The first injection was given $24 \mathrm{~h}$ after the cells' implantation. The site of injection was marked. The subsequent administrations were repeated at $72 \mathrm{~h}$ intervals. During the period of treatment, tumour volume $(V)$ was calculated by the following formula: $V=$ width $^{2} \times$ length $\times 0.5$ (Yanase et al, 1993). At day 22, all animals were killed and the tumours were excised and weighed.

Animal studies were conducted in accordance with the Italian regulation for experimentation on animals (Workman et al, 1998). All in vivo experiments were carried out with ethical committee approval and met the standards required by the UKCCCR guidelines. No mice showed signs of wasting or other signs of toxicity.

\section{Substances}

BS-RNase was purified from bovine seminal vesicles as previously reported (D'Alessio et al, 2001). HHP2-RNase and HP-RNase were prepared and purified as described (Di Gaetano et al, 2001). Doxorubicin and RNase A were purchased from Sigma Chemical Co. (St Louis, MO, USA). All chemicals used were of reagent grade. The disposable materials used for cell culture were from Nunc (Mascia-Brunelli, Milano, Italy). Nude mice were purchased from Charles River Italia (Calco, Italy).

\section{RESULTS}

\section{Selective cytotoxicity of BS-RNase and HHP2-RNase for thyroid cancer cells}

The experiments reported in this paper were aimed at: (i) testing the possibility that the strength of the antineoplastic action of ribonucleases could be directly correlated with the degree of tumour cell malignancy; (ii) comparing the effects of RNases with those of doxorubicin, a conventional anticancer drug. This has been made possible by the use of rat and human cell systems, carrying well-characterised genetic lesions and displaying progressively increasing malignancy. All the used cell models refer to a specific epithelial tumour type, that is, carcinomas derived from 
thyroid epithelial follicular cells. The main biological properties of cell lines are summarised in Table 1, where they are subdivided into three different sets. The first one is represented by normal rat thyroid follicular FRTL-5 cells, which maintain the differentiated phenotype (Ambesi-Impiombato et al, 1980) and their in vitro transformed derivatives (FRTL- $5 v$-src and $v$-Ki-ras) obtained by retroviral transduction (Fusco et al, 1987). The second set is represented by TK- 6 and MPTK-6, established in culture from primary thyroid carcinoma and lung metastasis, respectively, of rats subjected to intrathyroid injection of the $v$-Ki-ras-carrying retrovirus (Portella et al, 1989). The third set comprised normal human differentiated P5 thyrocytes (Curcio et al, 1994), normal human primary HDF fibroblasts, two papillary carcinoma-derived (TPC1 and NPA) and two anaplastic carcinoma-derived cell lines (Cal62 and ARO). The NPA cell line carries a double deletion of the p53 gene and an activating V599E point mutation in the B-Raf oncogene (Fagin et al, 1996; Kimura et al, 2003). Cal62 and ARO cells carry a mutated form of p53; the Cal62 cell line carries, in addition, a mutated N-ras gene (Namba et al, 1990; Fagin et al, 1993; Salvatore et al, 1996; Vecchio and Santoro, 2000). TPC1 cells carry a paracentric inversion of chromosome 10 causing the recombination of the tyrosine kinase-encoding domain of the ret receptor to the $5^{\prime}$-terminal region of the $\mathrm{H} 4$ gene, leading to the generation of the ret/ptc1 oncogene (Ishizaka et al, 1990), a lesion commonly found in papillary carcinomas (Grieco et al, 1990).

We compared cell growth properties, colony-forming efficiency in soft agar and tumorigenicity upon s.c. injection in nude mice of the various cell lines; the results are reported in Table 1. Normal FRTL-5, P5 and HDF cells and thyroid papillary carcinomaderived TPC1 cells did not show malignant features. TK-6 and FRTL-5- $v$-src cells showed an intermediate degree of malignancy, being able to grow in a semisolid medium and to induce tumours with long latency. MPTK-6, FRTL-5- $v$-Ki-ras, Cal 62, NPA and ARO cells displayed a highly malignant phenotype, as shown by their great efficiency to form colonies in soft agar and to induce tumours with short latency in nude mice (Table 1).

We tested the effects of BS-RNase and HHP2-RNase on all these cell lines in comparison to doxorubicin. Sensitivity to the compounds was expressed as $\mathrm{IC}_{50}$ (the concentration inhibiting $50 \%$ of the colony-forming efficiency) and is reported in Table 1.
$\mathrm{IC}_{50}$ values were determined from the curves (Figure 1) obtained by plotting the colony-forming efficiency $v s$ the logarithm of drug molarity (the curves for P5, NPA and Cal62 are not shown). The results demonstrated a selective cytotoxicity of the two dimeric RNases towards cancer cells, the strength of the activity being directly related to the malignant phenotype of tumour cells. The most malignant cells (MPTK-6, FRTL-5- $v$-Ki-ras, NPA, Cal 62 and ARO) showed the lower values of $\mathrm{IC}_{50}$ (Table 1). No toxic effects were observed on normal counterparts of all cell systems. In contrast, an inverse relationship was observed between doxorubicin cytotoxicity and the degree of cell malignancy, the activity of doxorubicin being maximal against the normal cells (FRTL-5, HDF and P5 cells) (Table 1, Figure 1).

\section{BS-RNase and HHP2-RNase induce apoptosis in tumour cells}

We investigated the nature of cell death induced by treatment with RNases. Cells were analysed for the presence of fragmented DNA with the characteristic pattern of internucleosomal ladder, suggestive of apoptosis. As shown in Figure 2, treatment with BS-RNase and HHP2-RNase, $72 \mathrm{~h}$ at $1.8 \mu \mathrm{M}\left(50 \mu \mathrm{g} \mathrm{ml}^{-1}\right)$, selectively promoted apoptosis in tumorigenic cells (MPTK-6, FRTL-5- $v$-Kiras, NPA and ARO cells), whereas apoptosis was undetected in the normal cell counterparts (FRTL-5 and HDF cells). Doxorubicin, instead $\left(1.8 \mu \mathrm{M}\right.$, i.e. $1 \mu \mathrm{g} \mathrm{ml}^{-1}$, for $\left.24 \mathrm{~h}\right)$, promoted apoptosis in normal cells and not in tumour cells. After $72 \mathrm{~h}$ of treatment, doxorubicin killed all cells, malignant and nonmalignant (not shown). No proapoptotic activity was exerted by monomeric RNases (RNase A and HP-RNase) (Figure 2).

The presence of apoptotic nuclear bodies was analysed by a fluorescence microscopy after staining with Hoechst 33258 (Figure 3). In these experiments, we utilised the human cell line displaying the most malignant phenotype (ARO cell line). When this cell line was treated with either dimeric ribonuclease, it showed the characteristic chromatin condensation and margination and many fragmented nuclei. Again, monomeric RNase A and HP-RNase treatment did not cause any change in the nuclear morphology and number of cells (Figure 3). A quantitative estimation of BS-RNase- and HHP2-RNase-induced apoptosis

Table I Biological properties of the thyroid-derived cell lines used in this study and their sensitivity to doxorubicin and RNases

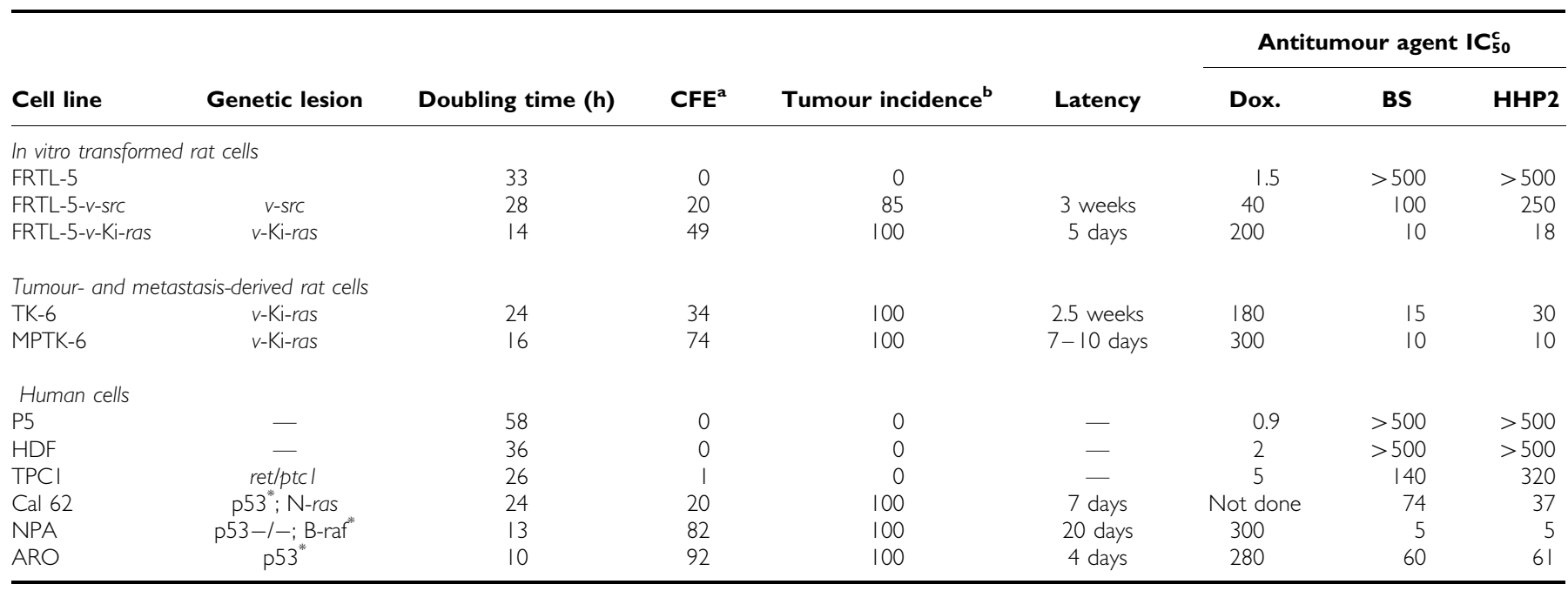

${ }^{a}$ Colony-forming efficiency was measured in agar and calculated by the formula: (number of colonies formed/number of plated cells) $\times 100$. Colonies larger than 64 cells were scored after $2-3$ weeks. ${ }^{b}$ Tumorigenicity was assayed by injecting $10^{6}$ cells into either nude mice or syngenic rats. The incidence (\%) was calculated as the per cent of animals with tumours over the total number of animals tested. 'The inhibiting concentration values $\left(\mathrm{IC}_{50}\right)$ were determined by the colony-forming assay and are expressed as $\mathrm{nM}$ concentrations. Values are means \pm s.d. of triplicate determinations from three independent experiments. " Presence of a mutated protein. 


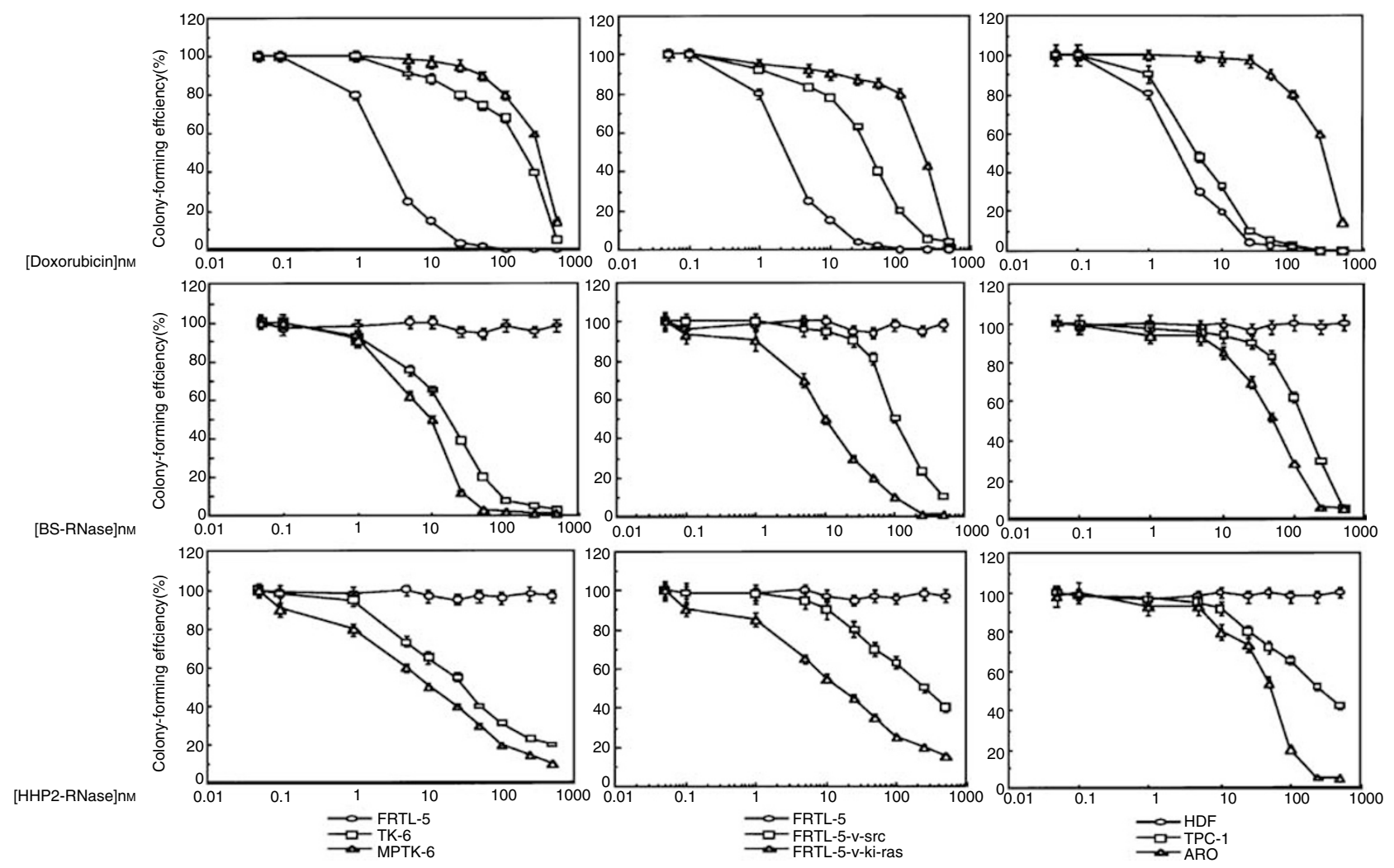

Figure I Cell survival of malignant and nonmalignant cell lines treated with the increasing concentration of doxorubicin, BS-RNase or HHP2-RNase. The average results \pm s.d. of three independent determinations. Cells were exposed to each molecule for $24 \mathrm{~h}$. After 3 weeks, cell survival was measured by counting colony-forming units.

gave values of $70 \pm 20$ and $90 \pm 20 \%$, respectively, of apoptotic cells. Similar results were obtained when the NPA cell line was used (data not shown).

\section{Antitumoral effects of BS-RNase and HHP2-RNase in nude mice}

We utilised ARO cells, characterised by a very short latency period for tumour growth in mice, to assess the antineoplastic activity of ribonucleases in vivo in mice bearing human thyroid neoplastic cells. Nude mice, inoculated with $1 \times 10^{6}$ ARO cells s.c., were treated with six injections in the peritumoral area of BS-RNase or HHP2-RNase $\left(20 \mu \mathrm{gg}^{-1}\right.$ of body weight). Administrations were repeated at $72 \mathrm{~h}$ intervals. A group of control mice was treated with pancreatic RNase A with the same protocol and dose; another control group was injected with PBS alone. As shown in Figure 4, the antitumoral effects of both BS-RNase and HHP2-RNase were clearly evident during the whole period of mice treatment. In particular, the latency period for tumour appearance was highly prolonged in treated mice, reaching 14 and 18 days, respectively. At the end of the experiment, the average weight of the tumours from mice treated with BS-RNase and HHP2-RNase was 15 and $10 \%$ ( 85 and $90 \%$ of growth inhibition, respectively) with respect to the average weight of tumours grown in untreated mice or in mice treated with RNase A.

Finally, we sought to determine the toxicity of BS-RNase in healthy mice. Six injections intraperitoneal (i.p.) of $20 \mu \mathrm{gg}^{-1}$ of body weight of BS-RNase at $72 \mathrm{~h}$ intervals did not cause any effects on the survival of mice. The only side effect was a diminished body weight (20\% reduction) with respect to untreated mice (data not shown).

\section{DISCUSSION}

We have used a well-controlled thyroid cell model system to demonstrate specificity for malignant cells of the cytotoxic and proapoptotic effects exerted by two dimeric ribonucleases. The in vitro results were corroborated by a strong antitumour action of both RNases against tumours obtained by the injection of malignant cells in nude mice. Results from Phase II and III clinical trials in which onconase was used as the antitumour agent (Juan et al, 1998; Mikulski et al, 2002) support our belief that certain RNases exert a strong cytotoxicity towards cancer cells (Mikulski et al, 2002). However, onconase, at variance with the two ribonucleases that have been used in the present paper, has been shown to exert a cytotoxic effect also towards noncancerous cells and, at high concentrations, it leads to renal toxicity in mice (Haigis et al, 2003). The nature of cell death for both BS-RNase and HHP2-RNase has been found to be apoptotic. In fact, we have recently shown that BS-RNase and HHP2-RNase treatment triggers the activation of the execution caspase-3 (Spalletti-Cernia et al, 2003).

The availability of a genetically well-defined system of thyroid normal and tumour cells in our laboratory allowed us to perform a systematic study of the activities of BS-RNase and HHP2-RNase in comparison with the known chemotherapeutic drug doxorubicin. The cell systems used are representative of the different degrees of aggressiveness found in the various human thyroid tumours. Indeed, human thyroid carcinomas vary from the asymptomatic microcarcinoma to the differentiated carcinoma, to the anaplastic carcinomas, one of the most aggressive human cancers (Hedinger et al, 1989). Doxorubicin alone, and in combination with cisplatin, is the most widely used therapeutic agent for this last category of thyroid carcinomas; however, it does not improve survival in 


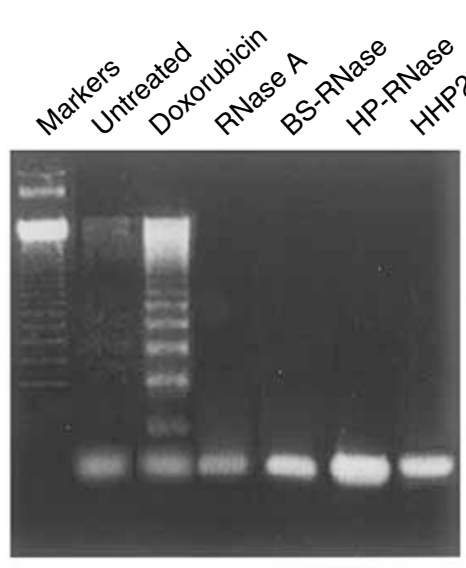

FRTL-5
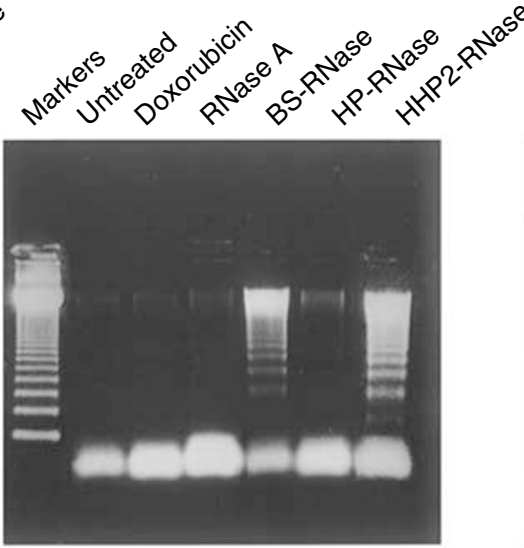

FRTL-5-v-Ki-ras

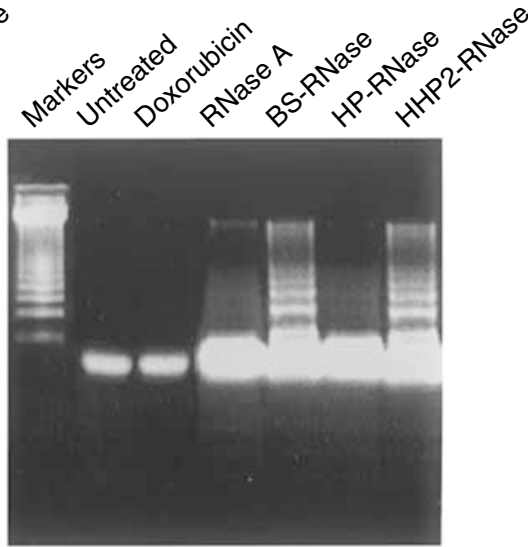

MPTK-6

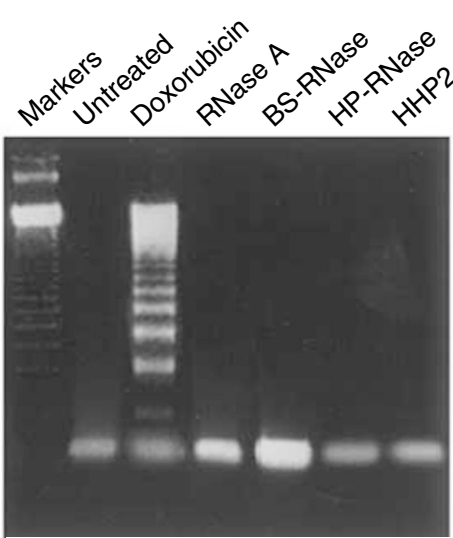

HDF
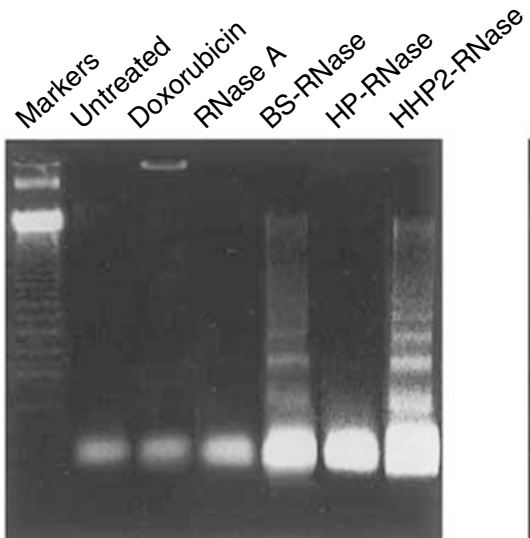

NPA

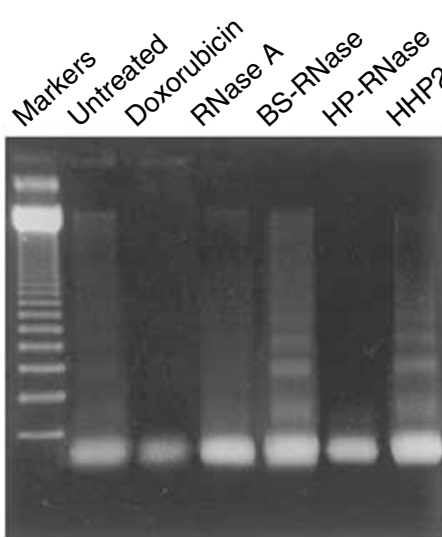

ARO

Figure 2 Analysis of DNA fragmentation in the malignant and nonmalignant cell lines treated with doxorubicin, BS-RNase or HHP2-RNase. Markers: molecular weight markers (I23-bp multimers). These data are representative of at least three independent experiments.

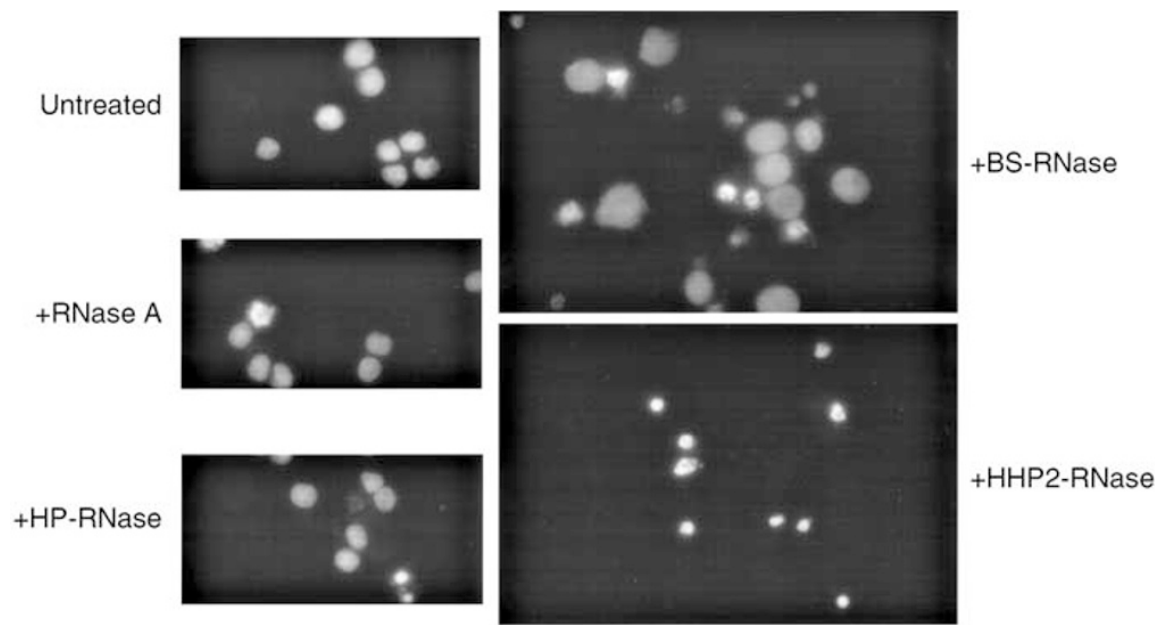

Figure 3 Fluorescence microscopy analysis of ARO cells treated with RNases. ARO cells were exposed for $72 \mathrm{~h}$ to the RNase under test (I.8 $\mu \mathrm{M}$ ). Cells were fixed and stained with Hoechst 33258 to reveal the nuclear signs of apoptosis and photographed $(\times 360)$.

anaplastic carcinoma patients (Hedinger et al, 1989; Rosai et al, 1992). The findings reported here demonstrate that the strength of cytotoxic and apoptotic activity of RNases exerted on cells grown in vitro was directly related to the degree of cell malignancy. On the contrary, doxorubicin showed its maximal cytotoxic and apoptotic effect against normal cells.
Unlike doxorubicin, BS-RNase and HHP-2 RNase are not known to induce, nor do they appear to be influenced by, the multidrugresistant phenotype, one of the most important mechanisms responsible for recurrences and metastatic invasion after chemotherapy. Indeed, MPTK-6 cells, highly susceptible to RNases, show the presence of a multidrug-resistant phenotype that is 


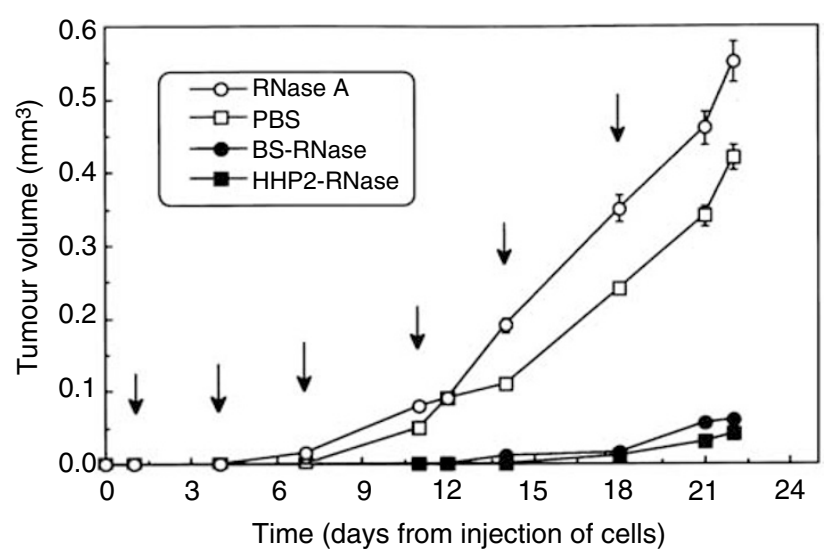

\begin{tabular}{|c|c|c|c|}
\hline Treatment & Latency (days) & $\begin{array}{c}\text { Tumour weight } \\
(\mathrm{g} \pm \text { S.E.M })\end{array}$ & Inhibition (\%) \\
\hline PBS & 4 & $0.42 \pm 0.02$ & - \\
\hline RNase A & 4 & $0.55 \pm 0.01$ & - \\
\hline BS-RNase & 14 & $0.06 \pm 0.002$ & 85 \\
\hline HHP2-RNase & 18 & $0.04 \pm 0.002$ & 90 \\
\hline
\end{tabular}

Figure 4 Time-dependent effect of BS-RNase (-0) and HHP2RNase (-ם) on tumour growth in mice inoculated s.c. (day 0) with $I \times 10^{6}$ ARO cells. RNases were administered in the peritumoral area six times at $72 \mathrm{~h}$ intervals as indicated by the arrows. Controls were treated with PBS $(\square-\square)$ or RNase A (O-O). Latency periods and means of the weights of the tumours excised at the end of each treatment are reported in the table inset.

independent from the gp170 glycoprotein (Spalletti-Cernia et al, 1995).

Another important feature is that both RNases exert their cytotoxicity independent of the genetic lesions present in the target cancer cells. Here, we show that they exhibit a similar cytotoxic activity against cells bearing Ki-ras (FRTL5- $v$-Ki-ras and MPTK-6), $\mathrm{N}$-ras (Cal62) and B-raf (NPA) mutations as well as against cells bearing p53 alterations. The most malignant cells, which are highly sensitive to both RNases, are representative of the whole possible spectrum of the p53 status. NPA cells show lack of any functional p53 (Fagin et al, 1996), ARO and Cal62 show a heterozygous mutant p53 (Fagin et al, 1993), whereas TK-6 and MPTK-6 have a normally functioning p53 (Vecchio et al, unpublished observations). Therefore, RNases cytotoxicity is also independent of the p53 status of the malignant cell line used. This has important therapeutic implications since it is well known that the majority of human cancers bear inactive p53 that renders tumour cells unable to undergo drug-induced apoptosis. In particular, mutations of p53 are the common feature of anaplastic thyroid cancer (Fagin et al, 1993). The in vitro results are strengthened by in vivo experiments in which peritumoral injection of both RNases inhibited the growth of human anaplastic thyroid cancer cells transplanted into nude mice and grown s.c. The protocol of RNases administration 1 day after the implantation of the tumour cells may seem to be of little applicability in the clinic. However, it must be considered that the growth rate of the tumour cells injected in mice is much higher than that in humans. In addition, nude mice injected with the ARO cells rapidly die if untreated and their treatment therefore must begin very early after implantation.

\section{REFERENCES}

Ambesi-Impiombato FS, Parks LAM, Coon HG (1980) Culture of hormone dependent functional epithelial cells from rat thyroids. Proc Natl Acad Sci USA 77: $3455-3459$
For these reasons, 1 day after the s.c. implantation of the tumour cells in mice could well be considered equivalent to the initial phase of tumour growth in humans and could coincide with the beginning of a potential therapy. Moreover, RNase or other antineoplastic drug administration in the peritumoral area has been successfully used previously for the treatment of rat (Laccetti et al, 1994) or human thyroid tumour cells (Carlomagno et al, 2002; Barzon et al, 2002, 2003). Obviously, the applicability of RNases in clinical situations and the site of administration of the antitumour molecules would depend largely on the type of the tumour, on its localisation and on the tumour growth rate. However, it is important to note that we have already shown that BS-RNase is capable of exerting a strong antitumour effect even when administered i.p. in a different in vivo experimental mouse system (Laccetti et al, 1994). Finally, it is important to underline that the peritumoral injection of RNase did not cause any adverse effect, such as death, body weight loss or changes in the physical appearance or behaviour of the treated mice. This is at variance with the slightly toxic effect ( $20 \%$ body weight reduction) observed with i.p. injections of BS-Rnase (see Results section). This further supports the choice of using peritumoral injections of the ribonucleases in the experimental system described here.

Furthermore, it must be considered that, in particular, human anaplastic thyroid tumours may represent a very suitable type of human tumour candidate for treatment with peritumoral or intratumoral injection of antineoplastic drugs. In fact, due to its late metastatic spreading, its severe local invasion and its relatively easy accessibility from the outside, this tumour lends itself in an ideal way to the peritumoral or intratumoral treatment such as the one described in this paper. Finally, it is important to consider that there are indeed already studies in the literature concerning clinical trials of human gliomas treated by using peritumoral or intratumoral injections of suicide and cytokine genes (Palù et al, 1999). It is interesting to note that a phase I clinical trial has been conducted by the same group for the treatment of human anaplastic thyroid carcinomas with peritumoral or intratumoral injections of the same genes (Palù, personal communication).

In conclusion, the dimeric RNases can be considered as drugs suitable for the development of novel alternative therapeutic agents against anaplastic thyroid tumours, to overcome the poor responsiveness of this type of tumour to conventional chemotherapeutic drugs, such as doxorubicin.

\section{ACKNOWLEDGEMENTS}

We thank J Gioanni for providing the Cal62 cell line, JA Fagin for providing ARO, NPA and TPC1 cell lines and FS AmbesiImpiombato and F Curcio for providing the P5 cell line. We are grateful to $\mathrm{C}$ Garbi for the fluorescence analysis and to $\mathrm{G}$ Tortora and $\mathrm{F}$ Ciardiello for a critical reading of the paper. We thank F D'Agnello and M Berardone for the artwork and S Sequino for animal care. We are indebted to N Tsuchida and GB Ferrara for the p53 mutation analyses. Grants or fellowships that supported the writing of the paper are Associazione Italiana per la Ricerca sul Cancro (AIRC), the Italian Ministry of Instruction, University and Research (MIUR) and the Italian Ministry of Health. DSC and RS were recipients of a fellowship of the BioGeM s.c.ar.l. (Biotecnologia e Genetica Molecolare nel Mezzogiorno d'Italia) consortium. DSC was also supported by a fellowship from the European Community-European Social Fund.

Antignani A, Naddeo M, Cubellis MV, Russo A, D’Alessio G (2001) Antitumor action of seminal ribonuclease, its dimeric structure, and its resistance to the cytosolic ribonuclease inhibitor. Biochemistry 40: 3492-3496 
Bange J, Zwick E, Ullrich A (2001) Molecular targets for breast cancer therapy and prevention. Nat Med 7: 548-552

Barzon L, Bonaguro R, Castagliuolo I, Chilosi M, Franchin E, Del Vecchio C, Giaretta I, Boscaro M, Palù G (2003) Gene therapy of thyroid cancer via retrovirally-driven combined expression of human interleukin-2 and herpes simplex virus thymidine kinase. Eur J Endocrinol 148: 73-80

Barzon L, Bonaguro R, Castagliuolo I, Chilosi M, Gnatta E, Parolin C, Boscaro M, Palu G (2002) Transcriptionally targeted retroviral vector for combined suicide and immunomodulating gene therapy of thyroid cancer. J Clin Endocrinol Metab 11: 5304-5311

Beintema JJ, Breukelman HJ, Carsana A, Furia A (1997) Evolution of vertebrate ribonucleases: ribonuclease A superfamily. In Ribonucleases: Structure and Function, D'Alessio G, Riordan JF (eds) pp 245-269. San Diego: Academic Press

Bracale A, Spalletti-Cernia D, Mastronicola MR, Castaldi F, Mannucci R, Nitsch L, D'Alessio G (2002) Essential stations in the intracellula pathways of cytotoxic bovine seminal ribonuclease. Biochem J 362: 553 560

Carlomagno F, Vitagliano D, Guida T, Ciardiello F, Tortora G, Vecchio G Rjan AJ, Fontanini G, Fusco A, Santoro M (2002) ZD6474, an orally available inhibitor of KDR tyrosin kinase activity, efficiently blocks oncogenic RET kinase. Cancer Res 62: 7284-7290

Chabner BA, Boral AL, Multani P (1998) Translation research: walking the bridge between idea and cure - Seventeenth Bruce F. Cain Memorial Award lecture. Cancer Res 58: 4211-4216

Curcio F, Ambesi-Impiombato FS, Perrella G, Coon HG (1994) Long-term culture and functional characterization of follicular cells from adult normal human thyroids. Proc Natl Acad Sci USA 91: 9004-9008

D'Alessio G, Di Donato A, Piccoli R, Russo N (2001) Seminal ribonuclease: preparation of natural and recombinant enzyme, quaternary isoforms, isoenzymes, monomeric forms; assay for selective cytotoxicity of the enzyme. Methods Enzymol 341: 248-263

Di Gaetano S, D’Alessio G, Piccoli R (2001) Second generation antitumour human RNase: significance of its structural and functional features for the mechanism of antitumour action. Biochem J 358: 241-247

Fagin JA, Matsuo K, Karmakar A, Chen DL, Tang SH, Koeffler HP (1993) High prevalence of mutations of the p53 gene in poorly differentiated human thyroid carcinomas. J Clin Invest 91: 179-184

Fagin JA, Tang SH, Zeki K, Di Lauro R, Fusco A, Gonsky R (1996) Reexpression of thyroid peroxidase in a derivative of an undifferentiated thyroid carcinoma cell line by introduction of wild type p53. Cancer Res 56: $765-771$

Fiore L, Pollina LE, Fontanini G, Casalone R, Berlingieri MT, Giannini R, Pacini F, Miccoli P, Toniolo A, Fusco A, Basolo F (1997) Cytokine production by a new undifferentiated human thyroid carcinoma cell line, FB1. J Clin Endocrinol Metab 82: 4094-4100

Fusco A, Berlingieri MT, Di Fiore PP, Portella G, Grieco M, Vecchio G (1987) One- and two-step transformations of rat thyroid epithelial cells by retroviral oncogenes. Mol Cell Biol 7: 3365-3370

Gibbs JB (2000) Anticancer drug targets: growth factors and growth factor signaling. J Clin Invest 105: 9-13

Gioanni J, Zanghellini E, Mazeau C, Zhang D, Courdi A, Farges M, Lambert JC, Duplay H, Schneider M (1991) Caractérisation d'une lignée cellulaire humaine provenant d'un carcinome anaplasique de la thyroide. Bull Cancer 78: $1053-1062$

Grieco M, Santoro M, Berlingieri MT, Melillo RM, Donghi R, Bongarzone I, Pierotti MA, Della Porta G, Fusco A, Vecchio G (1990) PTC is a novel rearranged form of the ret proto-oncogene and is frequently detected in vivo in human thyroid papillary carcinomas. Cell 60: 557-563

Haigis MC, Kurten EL, Raines RT (2003) Ribonuclease inhibitor as an intracellular sentry. Nucleic Acids Res 31: 1024-1032

Halicka DH, Pozarowski P, Ita M, Ardelt WJ, Mikulski SM, Shogen K, Darzynkiewicz Z (2002) Enhancement of activation-induced apoptosis of lymphocytes by the cytotoxic ribonuclease onconase (Ranpirnase). Int $J$ Oncol 21: 1245-1250

Halicka HD, Murakami T, Papageorgio CN, Mittelman A, Mikulski SM, Shogen K, Darzynkiewicz Z (2000) Induction of differentiation of leukaemic (HL-60) or prostate cancer (LNCaP, JCA-1) cells potentiates apoptosis triggered by onconase. Cell Prolif 33: 407-417

Hedinger C, Williams ED, Sobin LH (1989) The WHO histological classification of thyroid tumors: a commentary on the second edition. Cancer 63: 908 -911

Hockenbery D, Nunez G, Milliman C, Schreiber RD, Korsmeyer SJ (1990) $\mathrm{Bcl}-2$ is an inner mitochondrial membrane protein that blocks programmed cell death. Nature 348: $334-336$
Hurley LH (2002) DNA and its associated processes as targets for cancer therapy. Nature 2: $188-200$

Ishizaka Y, Ushijima T, Sugimura Nagao M (1990) cDNA cloning and characterization of ret activated in a human papillary thyroid carcinoma cell line. Biochem Biophys Res Commun 168: 402-408

Juan G, Ardelt B, Li X, Mikulski SM, Shogen K, Ardelt W, Mittelmann A, Darzynkiewicz Z (1998) G1 arrest of U937 cells by onconase is associated with suppression of cyclin D3 expression, induction of p16INK4A, p21WAF1/CIP1 and p27KIP and decreased pRb phosphorylation. Leukemia 12: $1241-1248$

Kantor GJ, Mulkie JR, Hull DR (1978) A study of the effect of ultraviolet light on the division potential of human diploid fibroblasts. Exp Cell Res 113: $283-294$

Kimura ET, Nikiforova MN, Zhu Z, Knauf JA, Nikiforov YE, Fagin JA (2003) High prevalence of BRAF mutations in thyroid cancer: genetic evidence for constitutive activation of the RET/PTC-RAS-BRAF signaling pathway in papillary thyroid carcinoma. Cancer Res 63: $1454-1457$

Laccetti P, Portella G, Mastronicola MR, Russo A, Piccoli R, D’Alessio G, Vecchio G (1992) In vivo and in vitro growth-inhibitory effect of bovine seminal ribonuclease on a system of rat thyroid epithelial transformed cells and tumors. Cancer Res 52: $4582-4586$

Laccetti P, Spalletti-Cernia D, Portella G, De Corato P, D’Alessio G, Vecchio G (1994) Seminal ribonuclease inhibits tumor growth and reduces the metastatic potential of Lewis lung carcinoma. Cancer Res 54: $4253-4256$

Lee I, Lee YH, Mikulski SM, Lee J, Covone K, Shogen K (2000) Tumoricidal effects of onconase on various tumors. J Surg Oncol 73: 164-171

Leland PA, Staniszewski KE, Kim BM, Raines RT (2001) Endowing human pancreatic ribonuclease with toxicity for cancer cells. J Biol Chem 276: $43095-43102$

Mastronicola MR, Piccoli R, D’Alessio G (1995) Key extracellular and intracellular steps in the antitumor action of seminal ribonuclease. Eur $J$ Biochem 230: 242-249

Mikulski SM, Costanzi JJ, Vogelzang NJ, McCachren S, Taub RN, Chun $\mathrm{H}$, Mittelman A, Panella T, Puccio C, Fine R, Shogen K (2002) Phase II trial of a single weekly intravenous dose of ranpirnase in patients with unresectable malignant mesothelioma. J Clin Oncol 20: 274-281

Murthy BS, De Lorenzo C, Piccoli R, D’Alessio G, Sirdeshmukh R (1996) Effects of protein RNase inhibitor and substrate on the quaternary structures of bovine seminal RNase. Biochemistry 35: 3880-3885

Namba H, Rubin SA, Fagin JA (1990) Point mutations of ras oncogenes are an early event in thyroid tumorigenesis. Mol Endocrinol 4: $1474-1479$

Palù G, Cavaggioni P, Calvi P, Franchin E, Pizzato M, Boschetto R, Parolin C, Chilosi M, Ferrini S, Zanusso A, Colombo F (1999) Gene therapy of glioblastoma multiforme via combined expression of suicide and cytochine genes: a pilot study in humans. Gene Ther 6: 330-337

Pang XP, Hershman JM, Chung M, Pekary AE (1989) Characterization of tumor necrosis factor-alpha receptors in human and rat thyroid cells and regulation of the receptors by thyrotropin. Endocrinology 125: 17831788

Piccoli R, Di Gaetano S, De Lorenzo C, Grauso M, Monaco C, SpallettiCernia D, Laccetti P, Cinatl J, Matousek J, D’Alessio G (1999) A dimeric mutant of human pancreatic ribonuclease with selective cytotoxicity toward malignant cells. Proc Natl Acad Sci USA 96: 7768-7773

Portella G, Ferulano G, Santoro M, Grieco M, Fusco A, Vecchio G (1989) The Kirsten murine sarcoma virus induces rat thyroid carcinomas in vivo. Oncogene 4: $181-188$

Rosai J, Carcangiu ML, DeLellis RA (1992) Atlas of Tumor Pathology Tumors of the Thyroid Gland. 3rd series. Washington: Armed Force Institute of Pathology

Salvatore D, Celetti A, Fabien N, Paulin C, Martelli ML, Battaglia C, Califano D, Monaco C, Viglietto G, Santoro M, Fusco A (1996) Low frequency of p53 mutations in human thyroid tumors; p53 and Ras mutations in two out of fifty-six thyroid tumors. Eur I Endocrinol 134: 177-183

Saxena SK, Sirdeshmukh R, Ardelt W, Mikulski SM, Shogen K, Joule RJ (2002) Entry into cells and selective degradation of tRNAs by a cytotoxic member of the RNase A family. J Biol Chem 277: 15142 - 15146

Spalletti-Cernia D, D’Agnano I, Salvatore C, Portella G, Zupi G, Vecchio G, Laccetti P (1995) Transformation by $v$-ras oncogene correlates with an increased drug resistance in an epithelial thyroid cell system. Int J Oncol 6: $647-654$

Spalletti-Cernia D, Sorrentino R, Di Gaetano S, Arciello A, Garbi C, Piccoli R, D’Alessio G, Vecchio G, Laccetti P, Santoro M (2003) Antineoplastic 
ribonucleases selectively kill thyroid carcinoma cells via caspase-mediated induction of apoptosis. J Clin Endocrinol Metab 88: $2900-2907$

Vecchio G, Santoro M (2000) Oncogenes and thyroid cancer. Clin Chem Lab Med 38: $113-116$

Workman P, Twentyman P, Balkwill F, Balmain A, Chaplin D, Double J, Embleton J, Newell D, raymond R, Stables J, Stephens T, Wallace J (1998) United Kingdom Co-ordinating Committee on Cancer Research (UKCCCR) Guidelines for the welfare of animals in experimental neoplasia (Second Edition). Br J Cancer 77: 1-10
Wu Y, Mikulski SM, Ardelt W, Rybak SM, Youle RJ (1993) A cytotoxic ribonuclease. Study of the mechanism of onconase cytotoxicity. J Biol Chem 268: $10686-10693$

Yanase T, Tamura M, Fujita K, Koosama S, Tanaka S. (1993) Inhibitory effect of angiogenesis inhibitorTNP-470 on tumor growth and metastasis of human cell lines in vivo and in vitro. Cancer Res 53: $2566-2570$

Youle RJ, D'Alessio G (1997) Antitumor RNases. In Ribonucleases: Structure and Function, D'Alessio G, Riordan JF (eds) pp 491-514. San Diego: Academic Press 